\title{
THYROXINE METABOLISM IN THE NEPHROTIC SYNDROME ${ }^{1}$
}

\author{
By HOWARD RASMUSSEN 2 WITH THE TECHNICAL ASSISTANCE OF BETTY RAPP \\ (From the Department of Medicine of the Harvard Medical School and the Medical Services \\ of the Massachusetts General Hospital, Boston, Mass.)
}

(Submitted for publication October 31, 1955; accepted March 23, 1956)

The presence of hypometabolism and hypercholesterolemia in nephrosis suggests decreased thyroid function. Because of these abnormalities Epstein (1) treated a number of nephrotic patients with large doses of thyroid, and found that hypermetabolism could not be produced with daily doses of 4 to 5 grams of desiccated thyroid. ${ }^{3}$ Leiter, therefore, suggested (2) that the low basal metabolic rates and high concentrations of serum cholesterol in this disease were due to some cause other than hypothyroidism. The demonstration of low concentrations of protein-bound iodine in the serum of nephrotic patients (3) led Recant and Riggs to reinvestigate this problem (4). They found subnormal concentrations of serum $\mathrm{PBI}^{127}$, normal to high uptakes of $\mathrm{I}^{131}$ by the thyroid gland, low basal metabolic rates and high serum cholesterols in their nephrotic subjects. They also noted amounts of $\mathrm{PBI}^{127}$ in the urine as high as $36 \mu \mathrm{g}$. per day; a decrease in the thyroidal uptake of $\mathrm{I}^{181}$ following thyroid therapy; and the ability of the thyroid gland to respond to thyrotropic hormone as measured by a rise in the concentration of serum $\mathrm{PBI}^{127}$. On the basis of these findings, they postulated that in nephrosis the thyroid gland functions normally, that a deficiency of thyrotropic activity is unlikely, that the thyroxine-binding capacity of the plasma proteins is reduced, but that a normal supply of thyroid hormone is delivered to the peripheral tissues (i.e., presumably a normal amount is degraded each day). The low basal metabolic rate and high concentration of serum cholesterol were attributed to some factor other than decreased thyroid function. Although they found protein-bound iodine in the urine, they felt

\footnotetext{
1 Supported by grant AT(30-1)667 from the Atomic Energy Commission.

2 Dalton Scholar in Medicine, Massachusetts General Hospital.

3 Burroughs and Wellcome tablets of desiccated thyroid were used in these studies. Subsequent experience with this material in this laboratory has shown it to be of low and variable potency.
}

that any significant loss of hormone by this means could be compensated for by increased thyrotropic activity.

Their postulates concerning the abnormality of thyroxine-binding and the normal supply of hormone to the peripheral tissues were made on the basis of indirect evidence. A more direct assessment of these postulates is now possible with the use of thyroxine labeled with $\mathrm{I}^{131}$. The present study was undertaken to determine the abnormalities, if any, of thyroxine metabolism in nephrosis, and to test the validity of the above proposals.

\section{METHODS}

One normal subject and three adult patients with the nephrotic syndrome were studied. The diagnosis of the nephrotic syndrome was established in each case on the basis of the presence of gross edema, marked proteinuria, hypoalbuminemia, hypercholesterolemia, a typical electrophoretic pattern of the serum proteins, and the absence of azotemia. The syndrome had been manifest for at least nine months in one patient (A. M.) and for approximately four months in the other two. All three were presumed to be in the nephrotic stage of chronic glomerulo-nephritis.

As part of a previous study (5) each patient had received an intravenous tracer dose of radioactive iodine $\left(I^{12}\right)$ three to four weeks before the present study but no residual radioactivity was detectable in serum or urine before the injection of the radio-thyroxine.

From 5 to $15 \mu \mathrm{g}$. of L-thyroxine 4 labeled with 50 to $150 \mu \mathrm{c}$. $\mathrm{I}^{121}$ was administered intravenously to each patient. Plasma samples were obtained at 1, 6, 12 and 24 hours and then daily for 10 days. Twenty-four-hour urine, and three-day stool collections were obtained for 12 days. Duplicate $2-\mathrm{ml}$. aliquots of each urine and serum sample were prepared. The one was analyzed for total radioactivity and the other for protein-bound radioactivity. The latter was prepared by a modification of the method of Freedberg, Ureles, and Hertz (6), initial precipitation being accomplished with a 10 per cent solution of trichloracetic acid (TCA) and three washes with a 5 per cent solution of TCA. Two-ml. aliquots of the homogenized 3-day stool collections were analyzed for total radioactivity. Radioactivity in all samples was determined by means of a well-type scintillation crystal

4 Obtained from Abbott Laboratories, Chicago, Illinois. 
TABLE I

Summary of observed and derived values *

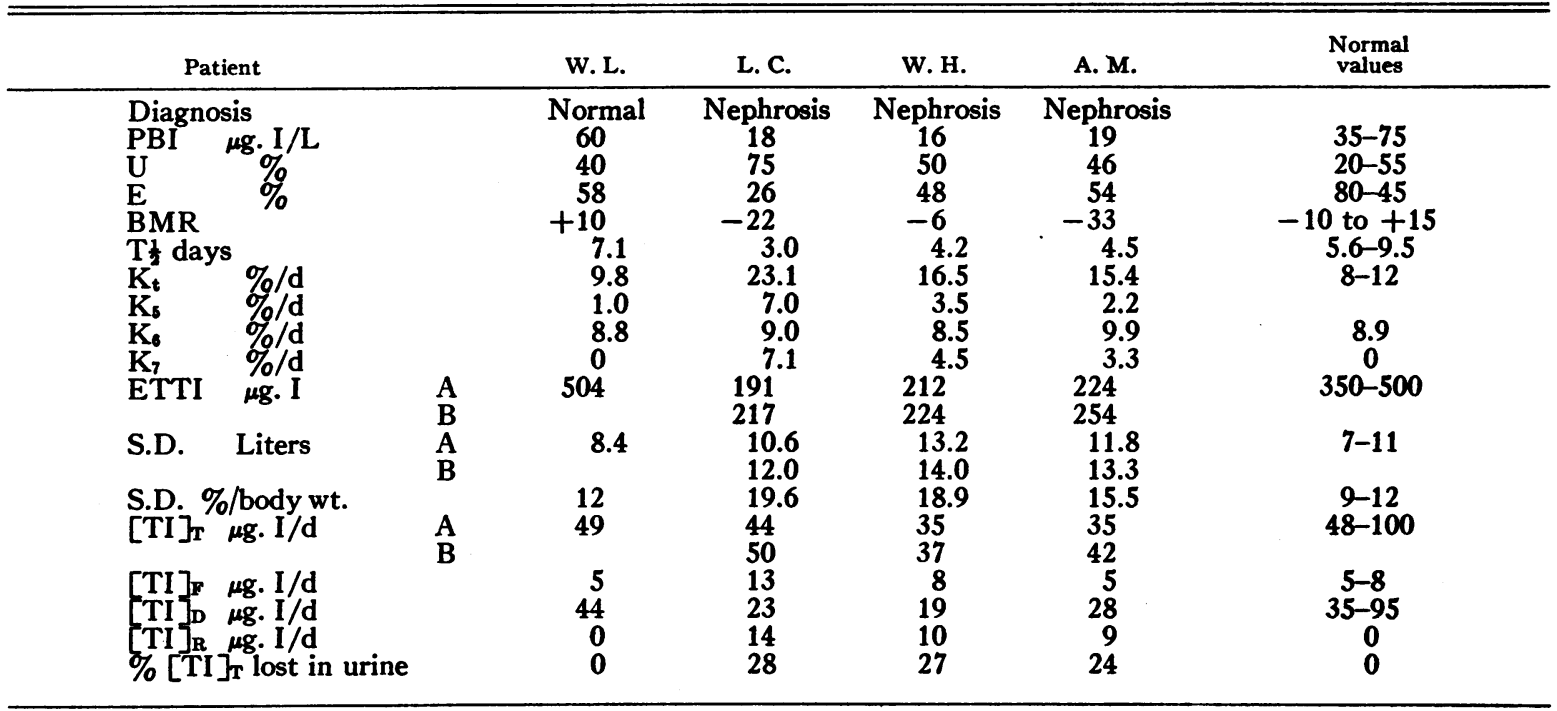

* See text for explanation of symbols.

which had a sensitivity of approximately $10^{6}$ counts per minute per microcurie (cpm per $\mu_{\mathrm{c}}$.). All counts were expressed as per cent of administered dose.

Three-ml. portions of serum, obtained on the second and seventh days, were extracted at $\mathrm{pH}$ 2-3 with butanol, evaporated, and chromatographed uni-dimensionally in butanol-dioxane-ammonia after the method of Gross, Leblond, Franklin, and Quastel (7). Thyroxine, triiodothyronine, and diiodotyrosine were identified by adding carrier and spraying with diazotized sulfanilic acid (7). Location of radioactivity was determined by radioautography. A single urine sample from each patient and a single sample of ascitic fluid from one patient (A. M.) was chromatographed in a similar manner. The radioactivity was located by radioautographs and the various spots were cut out and counted in the well-type scintillation crystal.

Serum samples and the ascitic fluid sample obtained on the third post-injection day were studied by zone electrophoresis in filter paper using the method of Kunkel and Tiselius (8). After staining the paper by the technique of Durrum (9) radioautographs were prepared.

Chemical analysis of iodine in serum was performed by a modification of the method of Barker (10).

Basal metabolic rates were determined in the usual manner except that the values were calculated on basis of ideal rather than actual weight.

\section{ANALYSIS OF DATA}

Two methods of analysis were employed to determine the size of the extrathyroidal thyroxine iodine pool (ETTI) and quantity of thyroxine iodine metabolized or turned over each day $\left([\mathrm{TI}]_{\mathrm{T}}\right)$.

Method A (Table I). The plasma disappearance curves of total and protein-bound radioactivity were plotted semilogarithmically (Figure 1) and analyzed by extrapolation techniques $(11,12)$. The half-time $(T 1 / 2)$ was estimated graphically. The fraction of the body's ETTI turned

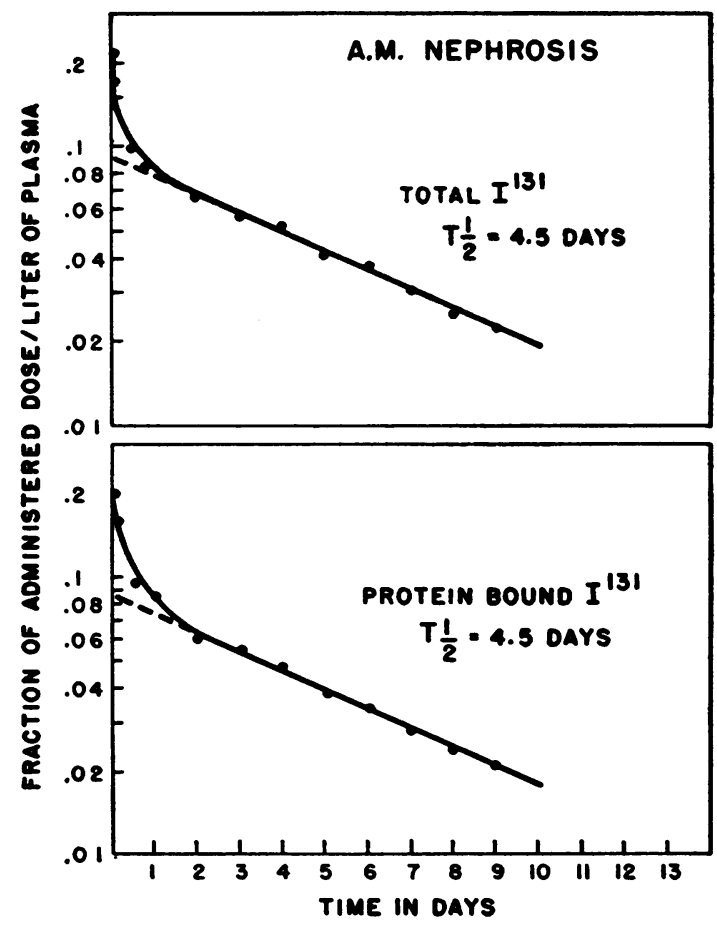

Fig. 1. The Disappearance Curves of Total and Protein-Bound Radioactivity in Plasma

See text for discussion. 
over each day $\left(\mathrm{K}_{\mathrm{T}}\right)$ was obtained from the known relationship

$$
\mathrm{K}_{\mathrm{T}}(\text { Fraction } / \text { day })=\frac{0.693}{\mathrm{~T} 1 / 2} \text { (days) }
$$

The apparent space of distribution (S.D.) of thyroxine was estimated by the extrapolation of the linear curve to zero time.

$$
\text { S.D. }=\frac{\text { Total Radioactivity }(\%)}{\text { Conc. Radioactivity }(\% / \mathrm{L}) \text { at } \mathrm{t}_{0}}
$$

This S.D. was also expressed as per cent of body weight. The ETTI pool was calculated,

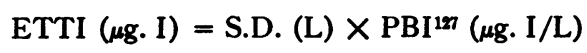

and from this the $[\mathrm{TI}]_{\mathrm{T}}$ obtained,

$$
[\mathrm{TI}]_{\mathrm{T}}(\mu \mathrm{g} . \mathrm{I} / \text { day })=\mathrm{K}_{\mathrm{T}} \text { (fraction/day) } \times \operatorname{ETTI}(\mu \mathrm{g} . \mathrm{I})
$$

The sources of error in such analytic methods are well known (13) and arise as a result of: 1) The use of nonhomogeneous material; 2) failure to observe the disappearance curves for a sufficient period of time; and 3) disproportionate metabolism of the labeled compound during the mixing period (early phase of curves in Figure 1). The first two sources of error were minimized in this study. Material was used which was 95 per cent "pure" chromatographically. This was further checked by measuring both protein-bound and total radioactivity in the plasma. As can be seen in Figure 1, the plasma disappearance curves of the total and protein-bound radioactivity were identical, and the concentration of proteinbound radioactivity of separate samples was 97 to 101 per cent of the total radioactivity. The early portions of the disappearance curves of the total and protein-bound radioactivity would have differed had a large percentage of inorganic $I^{131}$ existed in the injected material. The period of observation in each case was over 2 half-times, thus minimizing the chance of serious error in this direction. The third source of error noted above is inherent in the method, but in the present experiments probably intro-

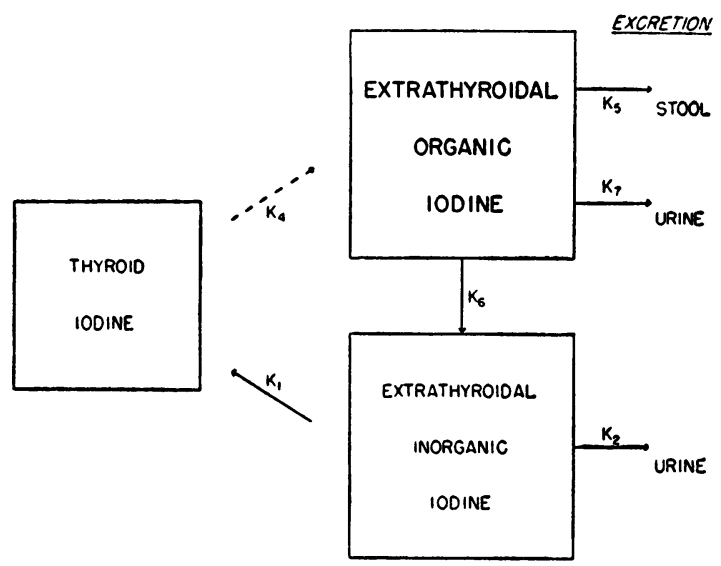

Fig. 2. An Assumed Model of Thyroxine Metabolism in Nephrotic Patients

See text for explanation. duced less than a 10 per cent error for S.D. and so did not greatly influence the other values obtained. The values of S.D., ETTI and [TI $]_{\text {r }}$ estimated for the control subject in this experiment, and those obtained for normal subjects by others $(11,12)$ are in agreement with estimates made by other analytic methods (14). Also the values obtained using biosynthesized organic iodine (15) are similar to those obtained utilizing thyroxine labeled in vitro $(11,15)$, as used in the present experiments.

Method B (Table I). In Figure 2 is represented an assumed model of thyroxine metabolism in the nephrotic subject (modified from Brownell (16)). Radiothyroxine $\left(\mathrm{Tx}^{*}\right)$ administered to such an individual enters the extrathyroidal organic iodine pool, ${ }^{5}$ from which it leaves either by being excreted in the feces (17) or urine (4) in the form of organic $\mathrm{PBI}^{181}$, or by being degraded in the peripheral tissues with release of inorganic $I^{181}$. The proportion of $\mathrm{Tx}^{*}$ leaving by each route will depend upon the rate constants $K_{6}, K_{0}, K_{7}$ which are the fraction of the extrathyroidal organic iodine pool turned over each day by fecal excretion, degradation, and urinary excretion (organic iodine), respectively. The inorganic $I^{131}$ liberated by degradation is either accumulated in the thyroid gland or excreted in the urine, and will be apportioned between the two depending on the rate constants $K_{1}$ and $K_{2}$ which are the fractions of the extrathyroidal inorganic iodine pool cleared per hour by thyroid and kidney, respectively. Since the rate of removal of $I^{131}$ from the plasma exceeds greatly the rate of degradation of $\mathrm{Tx}^{*}$, the rate of entry of $I^{181}$ into the urine or thyroid is governed by the rate of $\mathrm{Tx}^{*}$ degradation. As shown by Berson and Yalow (15), the "apparent renal plasma organic iodine clearance" can be estimated. This is the volume of plasma apparently cleared of degraded thyroxine by the kidney each day and is determined as follows,

App. Renal PBI ${ }^{131} \mathrm{Cl}$. $(\mathrm{L} / \mathrm{d})=\frac{\text { Urinary } \mathrm{I}^{181}(\% / \mathrm{d})}{\text { Mean Plasma PBI }{ }^{131}(\% / \mathrm{L})}$

The urinary inorganic $I^{131}$ was determined by subtracting PBI ${ }^{131}$ from total $I^{131}$.

Since

$$
\frac{\mathrm{K}_{1}}{\mathrm{~K}_{2}}=\frac{\mathrm{U}}{\mathrm{E}}
$$

where $U$ is the thyroidal uptake and $E$ the renal excretion of a tracer dose of $I^{181}$, the "apparent renal clearance" is directly proportional to $\mathrm{E}$, and the "apparent total clearance of organic iodine" by both kidney and thyroid is

$$
\text { App. Total PBI }{ }^{131} \mathrm{Cl} .=\frac{\text { App. Renal PBI }{ }^{131} \mathrm{Cl} \text {. }}{\mathrm{E}}
$$

Since $U$ and $E$ were determined in each patient shortly before the present studies (5), the above values could be calculated. The amount of thyroxine iodine degraded [TI $]_{D}$ each day was then estimated,

$[\mathrm{TI}]_{\mathrm{D}}(\mu \mathrm{g} . \mathrm{I} / \mathrm{d})=$ App. Total $\mathrm{PBI}^{131} \mathrm{Cl}$. (L/d) $\times \mathrm{PBI}^{127}$ ( $\left.\mu \mathrm{g} . \mathrm{I} / \mathrm{L}\right)$

In the ensuing discussion the extrathyroidal thyroxine and organic iodine pools are considered synonymous. This is not strictly true but can be considered so for present purposes. 
Determination of the "true renal PBI'181 clearance" (the volume of plasma cleared of $\mathrm{PBI}^{131}$ by the kidney each day) was accomplished similarly,

True Renal PBI ${ }^{121} \mathrm{Cl}$. (L/d) $=\frac{\text { Urinary PBI }{ }^{131}(\% / \mathrm{d})}{\text { Mean Plasma PBI }}$ and the daily renal excretion of thyroxine iodine $[\mathrm{TI}]_{\mathrm{R}}$ $[\mathrm{TI}]_{\mathrm{R}}(\mu \mathrm{g} . \mathrm{I} / \mathrm{d})=$ True Renal PBI'131 $\mathrm{Cl}$. (L/d) $\times \mathrm{PBI}^{187}(\mu \mathrm{g} . \mathrm{I} / \mathrm{L})$

Also the fecal $\mathrm{PBI}^{131}$ clearance ${ }^{6}$ was determined,

Fecal PBI ${ }^{131} \mathrm{Cl}$. (L/d) $=\frac{1}{3} \frac{\text { Fecal I'11 }(\% / 3 \mathrm{~d})}{\text { Mean Plasma PBI }}$

and the daily fecal excretion of thyroxine iodine $[\mathrm{TI}] \mathrm{F}$

$[\mathrm{TI}]_{\mathrm{F}}(\mu \mathrm{g} . \mathrm{I} / \mathrm{d})=$ Fecal PBI ${ }^{121} \mathrm{Cl} .(\mathrm{L} / \mathrm{d}) \times \mathrm{PBI}^{187}(\mu \mathrm{g} . \mathrm{I} / \mathrm{L})$

\section{Since}

and

$$
\mathrm{K}_{\mathrm{T}}=\mathrm{K}_{\mathbf{5}}+\mathrm{K}_{\mathbf{6}}+\mathrm{K}_{\mathbf{7}}
$$

$$
[\mathrm{TI}]_{\mathrm{T}}=[\mathrm{TI}]_{\mathrm{F}}+[\mathrm{TI}]_{\mathrm{D}}+[\mathrm{TI}]_{\mathrm{R}}
$$

values for ETTI, S.D., $K_{6}, K_{6}$ and $K_{7}$ could be derived,

$$
\begin{aligned}
\text { ETTI ( } \mu \text { g. I) } & =\frac{[T I]_{\mathrm{T}}(\mu \mathrm{g} . \mathrm{I} / \mathrm{d})}{\mathrm{K}_{\mathrm{T}}(\% / \mathrm{d})} \\
\text { S.D. }(\mathrm{L}) & =\frac{\mathrm{ETTI}(\mu \mathrm{g} . \mathrm{I})}{\mathrm{PBI}^{127}(\mu \mathrm{g} . \mathrm{I} / \mathrm{L})} \\
\mathrm{K}_{5} & =\mathrm{K}_{\mathrm{T}} \cdot \frac{[\mathrm{TI}]_{\mathrm{F}}}{[\mathrm{TI}]_{\mathrm{T}}} \\
\mathrm{K}_{6} & =\mathrm{K}_{\mathrm{T}} \cdot \frac{[\mathrm{TI}]_{\mathrm{D}}}{[\mathrm{TI}]_{\mathrm{T}}} \\
\mathrm{K}_{7} & =\mathrm{K}_{\mathrm{T}} \cdot \frac{[\mathrm{TI}]_{\mathrm{R}}}{[\mathrm{TI}]_{\mathrm{T}}}
\end{aligned}
$$

Each of the above clearance values was determined in each patient on four separate 24-hour periods and the arithmetical mean obtained. The mean plasma concentrations were determined graphically and checked by the formula

$$
\mathrm{P}=\frac{\mathrm{P}_{1}-\mathrm{P}_{2}}{2.3 \log \frac{\mathrm{P}_{1}}{\mathrm{P}_{2}}}
$$

which is the expression of the true mean of an exponential $\mathrm{dP} / \mathrm{dt}$. The calculated and graphically obtained mean concentrations were, for practical purposes, identical.

Since the estimation of the daily amount of thyroxine iodine degraded $[\mathrm{TI}]_{\mathrm{D}}$ involves the use of previously determined $U$ and $E$, this value may be in error if the true uptake is different from the observed, or if the uptake changed before the present study was initiated. Also, as shown in Figure 2, inorganic $I^{131}$ liberated by degradation and taken up by the thyroid may be synthesized into $\mathrm{Tx}^{*}$ and secreted into the circulation. However previous

${ }^{6}$ The nature of the fecal $I^{131}$ was not determined. In the calculations and in the subsequent discussion it has been assumed that the thyroxine iodine is cleared by the gastrointestinal tract in an organic form. studies with $I^{121}$ in these subjects (5) had shown that the turnover of $\mathrm{I}^{131}$ accumulated by the thyroid was slow, and that the PBI ${ }^{181}$ released into the circulation never reached a plasma concentration above .02 per cent per L. Such values would introduce an error of 2 to 3 per cent or less.

A final assumption was that these patients were in metabolic equilibrium as regards thyroxine secretion and turnover so that $[T I]_{\mathrm{T}}$ was assumed to equal the daily secretion of thyroxine iodine by the thyroid gland.

\section{RESULTS}

\section{Electrophoresis}

Zone electrophoretic analysis of the serum from each patient revealed similar patterns in all instances. There was a high alpha ${ }_{2}$-globulin and low albumin. All the radioactivity detected by radioautography appeared in a single band having a mobility intermediate between that of alpha ${ }_{1}$ - and alpha ${ }_{2}$-globulins. These results coincide with those obtained by similar analyses of normal serum after either intravenous administration of labeled thyroxine, the addition of labeled thyroxine in vitro, or the biosynthesis of labeled hormone (18-20).

A similar analysis of the ascitic fluid (patient A. M.) gave comparable results. The radioactivity appeared as a single band in the inter-alpha zone.

\section{Chromatography}

Chromatographic analysis of the two serum samples from each patient revealed that all the radioactivity detected by radioautography was located in the thyroxine spot. This was checked in one instance by cutting out the thyroxine and triiodothyronine spots, and measuring the radioactivity in each by means of a well-type scintillation crystal. The triiodothyronine spots contained less than 1 per cent of the radioactivity found in the thyroxine spots.

Radioautographs of the chromatograms of the butanol-extracted urine samples indicated that the radioactivity was located predominantly in the thyroxine spot with lesser amounts in the diiodotyrosine and inorganic iodide spots and none in the triiodothyronine spot. The developed spots were cut out and counted in the scintillation counter. The urinary diiodotyrosine was found to represent 6 to 8 per cent of the butanol-extractable organic iodine. This is comparable to values 


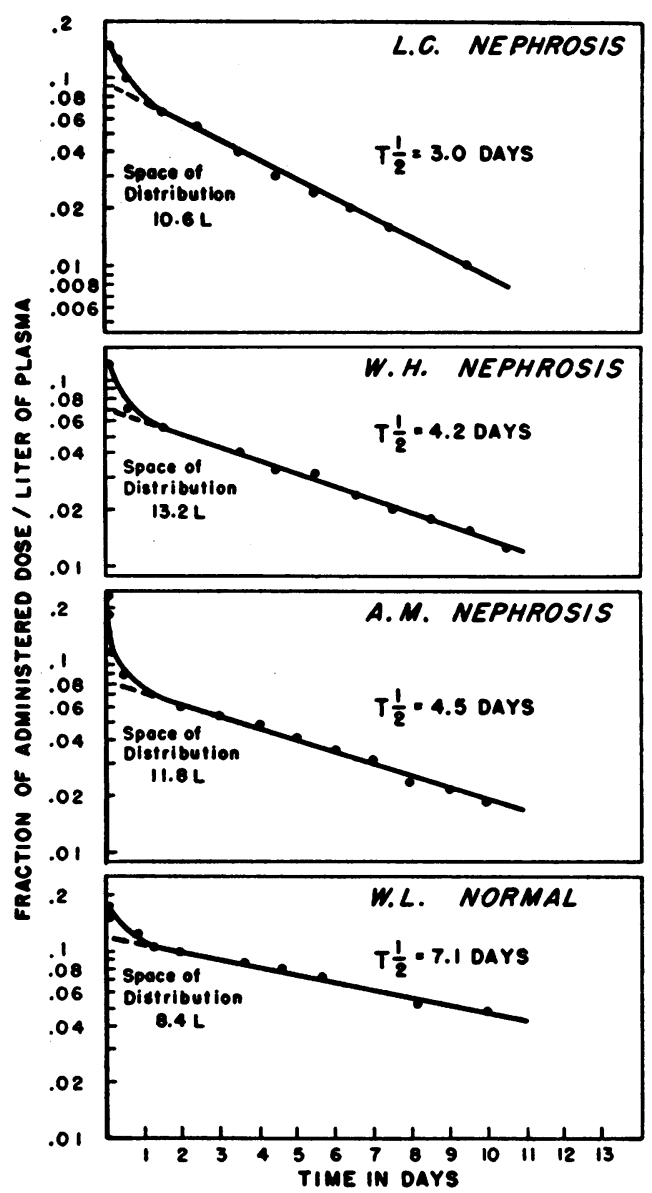

Fig. 3. Disappearance Curves of Protein-Bound Radioactivity in the Plasma of Three Nephrotic Subjects and One Normal Subject

reported for normals (21). A similar analysis of the supernatant after the precipitation of the urine with TCA revealed only inorganic $I^{\mathbf{1 8 1}}$. Therefore, the labeled diiodotyrosine was included as urinary $\mathrm{PBI}^{181}$ in the calculations of Method B. If this labeled diiodotyrosine came from the breakdown of thyroxine filtered through the renal glomeruli, no appreciable error would be introduced in the calculations of the "true" and "apparent" renal clearances of $\mathrm{PBI}^{131}$. On the other hand, the estimate of "true" renal clearance of $\mathrm{PBI}^{131}$ would be high and that of "apparent" renal clearance of $\mathrm{PBI}^{131}$ low, if the diiodotyrosine resulted from the degradation of thyroxine which had reached the renal cell from the post-glomerular blood stream.

When the single sample of ascitic fluid was ana- lyzed as above, the radioactivity was located entirely in the thyroxine spot.

\section{Serum and urine radioactivity}

The plasma disappearance curves of $\mathrm{PBI}^{131}$ for the normal and three nephrotic subjects are shown in Figure 3. The $T 1 / 2$ for the normal subject was 7.1 days, which is within the normal range ( 5.2 to 9.5 days; mean 6.5 days), as reported by others $(11,14,15)$. The $T 1 / 2$ in each nephrotic patient was less than normal ( 3.0 to 4.5 days).

The curves of appearance of both total and protein-bound radioactivity in the urine of patient W. H. are shown in Figure 4. As expected, they resemble closely the plasma disappearance curves and have similar T1/2's. As can be seen, the protein-bound $\mathrm{I}^{131}$ was a constant proportion of the total $\mathrm{I}^{181}$ excreted. Thus the previous assumptions, on which the calculations of Method B are based, appear valid.

\section{Derived values}

Table I lists the observed and derived values for each patient obtained by both methods of analysis.

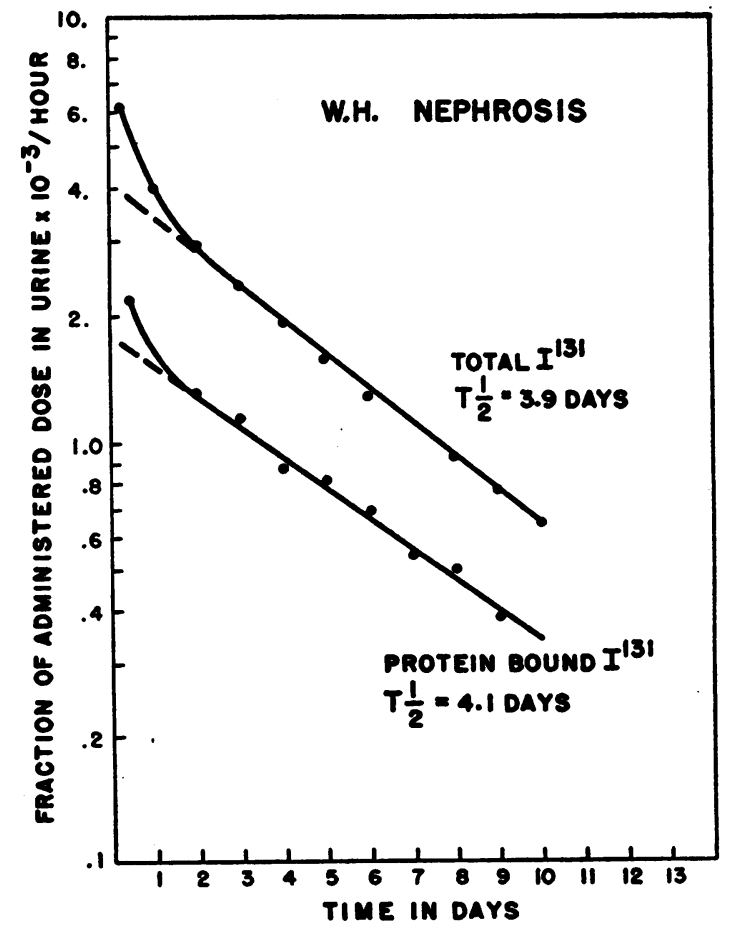

Fig. 4. Appearance Curves of Total and ProteinBound Radioactivity in the Urine of a Nephrotic SUBJECT 
Also listed are the values for the normal subject, and the average normal values obtained by others $(11,14,15)$. In the nephrotic patients the ETTI (191 to $224 \mu \mathrm{g}$. I) was less than normal (350 to $500 \mu \mathrm{g} . \mathrm{I})$ and the apparent space of distribution of thyroxine (10.6 to $13.2 \mathrm{~L}$.) was greater than normal ( 8 to 11 L.), particularly when expressed as per cent of body weight (nephrotics 15.5 to 19.6 per cent; normals 9 to 12 per cent). The daily turnover and synthesis of thyroxine iodine $[\mathrm{TI}]_{\mathbf{T}}$ was normal or only slightly decreased (nephrotics 35 to $44 \mu \mathrm{g}$. I/d ; normal 38 to $100 \mu \mathrm{g}$. $\mathrm{I} / \mathrm{d}$ ), but owing to the fact that there is a significant daily loss of organic iodine in the urine ( 9 to $14 \mu \mathrm{g}$. I), and an increased proportion of iodine lost in the stool (nephrotics 12 to 26 per cent; normal 10 to 12 per cent), the amount of hormonal iodine degraded each day (19 to $28 \mu \mathrm{g}$. I) is significantly less than normal ( 35 to $90 \mu \mathrm{g}$. I) and falls in the range reported for patients with panhypopituitarism (16.6 to $29.8 \mu \mathrm{g}$. I) (14). The percentage of ETTI turned over each day by degradation, $K_{6}$, is normal. This signifies that these nephrotic patients turned over thyroxine iodine at a more rapid rate than normal owing to the loss of organic iodine in the urine and a proportionately increased loss of iodine in the feces, but not because of an increased rate of peripheral degradation as found in thyrotoxic individuals $(14,15)$.

The values for ETTI, S.D. and $[\mathrm{TI}]_{\mathbf{T}}$ obtained by the two methods are approximately equal.

\section{DISCUSSION}

If, as proposed by Recant and Riggs (4), there is an abnormality in thyroxine-binding, the concentration of $\mathrm{PBI}^{127}$ in the serum would be low as seen; but the ETTI would be normal not low; the apparent space of distribution of thyroxine (S.D.) a great deal larger than that actually found; and the early phase of the plasma disappearance curves of radioactivity would have fallen more rapidly and to a lower level than observed in the present study. Thus the present data do not support their above-mentioned concept, but suggest that the low $\mathrm{PBI}^{127}$ in the serum is the result of other causes. This agrees with the conclusion of Robbins, Rall, and Petermann (22). These authors studied the thyroxine-binding capacity of nephrotic serum in vitro and found it to be slightly reduced but felt that this reduction was not sufficient to account for the lowered concentration of $\mathrm{PBI}^{127}$ in the serum.

Thyroid function as estimated in the present studies was "normal," in the sense that the uptake of inorganic $\mathrm{I}^{131}$ by the thyroid was in the normal range. Also the estimated daily secretion of thyroxine by the thyroid gland in each case approximated or was slightly less than that found in normal subjects. However, the amount of hormone undergoing peripheral degradation each day was estimated to be approximately one-half the normal amount. This apparent discrepancy between the quantity of thyroxine secreted by the thyroid and that degraded in the peripheral tissues is explained by the finding of a significant loss of thyroxine in the urine ( 25 to 30 per cent of that secreted) and a proportionately increased loss of thyroxine or its degradation products in the feces. If the amount of thyroxine degraded peripherally is directly related to the metabolic rate then these patients can be considered to have "tissue hypothyroidism" (i.e., less than the normal supply of thyroxine reaches and is degraded by their peripheral tissues). This might at least partially explain the hypometabolism observed in such patients.

The subnormal concentration of $\mathrm{PBI}^{\mathbf{1 2 7}}$ in the plasma of nephrotic individuals should result in an increased production of thyroid stimulating hormone (TSH) by the anterior pituitary gland, if as postulated (23), the plasma level of thyroid hormone is a significant factor in regulating the release of $\mathrm{TSH}$ from the pituitary. In turn, the increased TSH should stimulate the thyroid in such a way as to cause both an increased rate of uptake of inorganic iodine and an increased rate of thyroxine secretion. In spite of the low concentration of $\mathrm{PBI}^{127}$ in their serum, the thyroid glands of the present patients apparently are not secreting increased amounts of thyroxine. Presumably this could result from a functional abnormality in either the thyroid or anterior pituitary gland. By the administration of TSH, Recant and Riggs (4) were able to cause a rise in the concentration of $\mathrm{PBI}^{127}$ in the serum of two nephrotic subjects. This would suggest that the postulated defect lies in the pituitary gland, but does not exclude the possibility that the thyroid gland or the mechanism controlling thyroxine release is less sensitive to a physiological amount of TSH. 
The finding of a normal or high thyroidal uptake of $I^{131}$ would appear to be inconsistent with the proposed pituitary defect. Several factors may explain this apparent inconsistency. In the first place, it is obvious that there is not an absolute lack of TSH activity since the rate of hormonal secretion is maintained at nearly normal levels. Secondly, although the uptake of $\mathrm{I}^{131}$ is normal or high, the thyroidal clearance of $I^{131}\left(K_{1}\right)$ appears normal ( 3.0 to 5.0 per cent per $\mathrm{hr}$.) (5). This is in contrast to values found in states of supposed increased anterior pituitary activity such as iodine deficiency or thyrotoxicosis ( 8 to 12 per cent per hr.). In other words, the normal or high uptake of $\mathrm{I}^{131}$ results not from an increased thyroidal clearance $\left(\mathrm{K}_{1}\right)$, but from a decreased renal clearance of $I^{131}\left(K_{2}\right)$. Thirdly, it has been shown (24) that the iodine accumulating function of the thyroid gland is at least partially independent of anterior pituitary stimulation, varying with the iodine content of the diet in hypophysectomized animals. The reason for this presumed lack of augmented TSH output is not clear, but in these patients who are chronically ill and possibly protein-depleted a disturbance in pituitary function similar to that seen in chronic human malnutrition (25) seems possible.

As indicated by Recant and Riggs (4) and confirmed by Cruchaud, Mahaim, Scazziga, and Vannotti (26), some patients with this syndrome have abnormally high thyroidal $\mathrm{I}^{131}$ accumulation gradients or conversion indices in contradistinction to the normal thyroidal clearances observed in the present subjects (these three measurements, although expressed differently, measure the same parameter of thyroid function). It is possible that in such individuals the pituitary-thyroid axis is able to respond to the increased loss of thyroxine and thereby attempt to maintain an euthyroid state. This may also explain why some patients with this syndrome have normal concentration of protein-bound iodine in their serum. The authors wish to emphasize the point that all the subjects of the present investigation were adults whose disease was chronic and in whom the measureable indices of the disease (body weight, degree of albuminuria, serum concentration of albumin and cholesterol, etc.) were nearly constant during the period of study. It is not surprising, therefore, that they formed a fairly uniform group as regards their metabolism of thyroxine. However, they were observed for only a brief period during the long evolution of their disease. The results of similar studies in other individuals with the nephrotic syndrome may well differ from those recorded herein, since it is more than likely that as the syndrome evolves progressive alterations in thyroid function occur. If this is the case, then the data obtained in studies of this nature will depend upon when, during the course of the disease, such studies are carried out. In other words, the authors suggest that the variations in thyroidal function occurring in the nephrotic syndrome are dynamic in nature and evolve as the syndrome evolves, and that only by further work will it be possible to completely define these sequential changes.

The results of the present investigation suggest that the low concentration of $\mathrm{PBI}^{127}$ in the serum of some patients with the nephrotic syndrome is a result of at least four factors:

1) a significant loss of organic iodine in the urine;

2) a proportionately greater loss of iodine in the feces;

3) dilution of the organic iodine present because of an expanded extracellular fluid volume, and

4) inability of the pituitary-thyroid axis to augment the output of thyroxine in the face of an apparent thyroxine deficiency.

\section{SUMMARY}

The metabolic fate of $\mathrm{I}^{131}$-labeled thyroxine in three patients with the nephrotic syndrome is described, and the following conclusions drawn:

1. The half-time of plasma disappearance $\left(\mathrm{T}^{1} / 2\right)$ of intravenously administered $\mathrm{I}^{131}$-labeled thyroxine is shorter than normal.

2. There is a significant loss of organic iodine in the urine, and a proportionately increased loss of iodine in the feces.

3. The organic iodine in the urine is primarily in the form of thyroxine, but a small percentage ( 6 to 8 per cent) exists as diiodotyrosine.

4. The transport of thyroxine by the plasma proteins appears normal. 
5. The amount of hormone degraded by the peripheral tissues is in the hypothyroid range, and this finding may explain in part the lowered basal metabolic rate seen in these patients.

6. There is an apparent defect in the response of the pituitary-thyroid axis to the lowered concentration of $\mathrm{PBI}^{127}$ in the serum.

The observations are discussed in the light of previous studies on iodine metabolism and thyroid function in nephrosis.

\section{ACKNOWLEDGMENTS}

The authors wish to express their gratitude to Dr. John Stanbury for supporting this work and for many helpful suggestions, and to Dr. Gordon Brownell for his assistance in analysis of the data. Also, one of the authors (H. R.) wishes to thank Dr. Walter Bauer for his help and encouragement.

\section{REFERENCES}

1. Epstein, A. A., Thyroid therapy and thyroid tolerance in chronic nephrosis. J.A.M.A., 1926, 87, 913.

2. Leiter, L., Nephrosis. Medicine, 1931, 10, 135.

3. Peters, J. P., and Man, E. B., The relation of albumin to precipitable iodine of serum. J. Clin. Invest., 1948, 27, 397.

4. Recant, L., and Riggs, D. S., Thyroid function in nephrosis. J. Clin. Invest., 1952, 31, 789.

5. Rasmussen, H., Powell, M., and Stanbury, J. B., Unpublished data.

6. Freedberg, A. S., Ureles, A., and Hertz, S., Serum level of protein bound radioactive iodine $\left(I^{121}\right)$ in the diagnosis of hyperthyroidism. Proc. Soc. Exper. Biol. \& Med., 1949, 70, 679.

7. Gross, J., Leblond, C. P., Franklin, A. E., and Quastel, J. H., Presence of iodinated amino acids in unhydrolyzed thyroid and plasma. Science, 1950, 111, 605.

8. Kunkel, H. G., and Tiselius, A., Electrophoresis of proteins on filter paper. J. Gen. Physiol., 1951, $35,89$.

9. Durrum, E. L., A microelectrophoretic and microionophoretic technique. J. Am. Chem. Soc., 1950, 72, 2943.

10. Barker, S. B., Determination of protein-bound iodine. J. Biol. Chem., 1948, 173, 715.

11. Sterling, K., Lashof, J. C., and Man, E. B., Disappearance from serum of $I^{101}$-labeled 1-thyroxine and 1-triiodothyronine in euthyroid subjects. J. Clin. Invest., 1954, 33, 1031.
12. Meszaros, J., and Robbins, R., Kinetics of proteinbound iodine release and utilization. Clin. Research Proc., 1954, 2, 85.

13. Berson, S. A., Yalow, R. S., Schreiber, S. S., and Post, J., Tracer experiments with $I^{121}$ labeled human serum albumin: distribution and degradation studies. J. Clin. Invest., 1953, 32, 746.

14. Ingbar, S. H., and Freinkel, N., Simultaneous estimation of rates of thyroxine degradation and thyroid hormone synthesis. J. Clin. Invest., 1955, 34, 808.

15. Berson, S. A., and Yalow, R. S., Quantitative aspects of iodine metabolism. The exchangeable organic iodine pool, and the rates of thyroidal secretion, peripheral degradation and fecal excretion of endogenously synthesized organically bound iodine. J. Clin. Invest., 1954, 33, 1533.

16. Brownell, G. L., Analysis of techniques for the determination of thyroid function with radioiodine. $J$. Clin. Endocrinol., 1951, 11, 1095.

17. Albert, A., and Keating, F. R., Jr., Metabolic studies with $I^{121}$ labeled thyroid compounds. Comparison of the distribution and fate of radioactive d-1thyroxine after oral and intravenous administration in the human. J. Clin. Endocrinol., 1949, 9, 1406.

18. Gordon, A. H., Gross, J., O'Connor, D., and PittRivers, R., Nature of the circulating thyroid hormone-plasma protein complex. Nature, 1952, 169, 19.

19. Deiss, W. P., Albright, E. C., and Larson, F. C., A study of the nature of the circulating thyroid hormone in euthyroid and hyperthyroid subjects by use of paper electrophoresis. J. Clin. Invest., 1952, $31,1000$.

20. Robbins, J., and Rall, J. E., Zone electrophoresis in filter paper of serum ${ }^{131}$ after radioiodide administration. Proc. Soc. Exper. Biol. \& Med., 1952, 81, 530.

21. Rall, J. E., Iodine compounds in the blood and urine of man. Van Meter Prize Award Essay. J. Clin. Endocrinol., 1950, 10, 996.

22. Robbins, J., Rall, J. E., and Petermann, M. L., Protein-binding of thyroxine in normal and nephrotic serum. J. Clin. Invest., 1954, 33, 959.

23. Means, J. H., The Thyroid and Its Diseases. 2nd ed., Philadelphia, Lippincott, 1948.

24. Halmi, N. S., Regulation of the rat thyroid in shortterm iodine deficiency. Endocrinology, 1954, 54, 216.

25. Zubirán, S., and Gómez-Mont, F., Endocrine disturbances in chronic human malnutrition. Vitamins \& Hormones, 1953, $11,97$.

26. Cruchaud, S., Mahaim, C., Scazziga, B., and Vannotti, A., Fonction thyroidienne et néphrose lipoidique. Schweiz. med. Wchnschr., 1954, 84, 478. 